\title{
Kualitas semen segar sapi Bali (Bos javanicus) pada kelompok umur yang berbeda
}

\author{
S. Prastowo ${ }^{1 \text { a }}$, P. Dharmawan, T. Nugroho, A. Bachtiar ${ }^{2}$ Lutojo $^{1}$, A. Pramono ${ }^{1}$ \\ ${ }^{I}$ Program Studi Peternakan, Fakultas Pertanian, Universitas Sebelas Maret, Surakarta. Jawa Tengah \\ ${ }^{2}$ Balai Besar Inseminasi Buatan Singosari, Malang. Jawa Timur \\ a email: prastowo@staff.uns.ac.id
}

\begin{abstract}
Abstrak
Penelitian ini bertujuan untuk mengetahui kualitas semen segar sapi Bali pada kelompok umur yang berbeda. Sampel yang digunakan berupa semen segar yang ditampung menggunakan vagina buatan dari 8 ekor pejantan sapi Bali, terbagi menjadi 2 kelompok umur yaitu 4 dan 7 tahun, di Balai Besar Inseminasi Buatan (BBIB) Singosari Malang, Jawa Timur. Periode penelitian dilakukan pada bulan September - November 2016. Parameter yang diamati meliputi volume (ml), pH, konsentrasi $\left(\mathrm{x} 10^{6} / \mathrm{ml}\right)$, motilitas $(\%)$, persentase spermatozoa hidup (L/D; \%), abnormalitas primer (\%) dan abnormalitas sekunder (\%). Untuk mengetahui perbedaan antar 2 kelompok umur, data kualitas semen dibandingkan menggunakan $t$-test. Hasil penelitian menunjukkan bahwa pada kelompok umur 4 dan 7 tahun masing-masing diperoleh volume $4,55 \pm 0,91 \mathrm{ml}$ dan $5,18 \pm 1,58 \mathrm{ml}, \mathrm{pH} 6,51 \pm 0,06$ dan $6,52 \pm 0,01$, konsentrasi $962,30 \pm 390,50 \times 10^{6} / \mathrm{ml}$ dan $1079,00 \pm 90,56 \times 10^{6} / \mathrm{ml}$, L/D $71,88 \pm 2,58 \%$ dan $72,02 \pm 1,35 \%$, motilitas $68 \pm 3,11 \%$ dan $66,04 \pm 6,30 \%$, abnormalitas primer $1,054 \pm 0,20 \%$ dan $0,93 \pm 0,14 \%$ serta abnormalitas sekunder $3,54 \pm 0,48 \%$ dan $4,24 \pm 0,31 \%$. Pada penelitian ini, umur pejantan berpengaruh secara nyata $(\mathrm{P}<0,05)$ pada volume dan abnormalitas sekunder. Berdasarkan hasil penelitian dapat disimpulkan bahwa pada kelompok pejantan sapi Bali umur 7 tahun menghasilkan volume semen dan abnormalitas sekunder lebih tinggi dibandingkan umur 4 tahun.
\end{abstract}

Kata kunci: sapi Bali, pengaruh umur, kualitas semen segar

\section{Age Effect on Bali Cattle (Bos Javanicus) Fresh Semen Quality}

\begin{abstract}
This study aims to know the effect of bull age on fresh semen quality in Bali cattle. For that, fresh semen samples were collected using artificial vagina from eight Bali cattle bulls which were divided into two groups age 4 and 7 years old. Bali cattle bulls were reared in Artificial Insemination Centre Singosari, Malang, East Java, Indonesia and this study was conducted from September until November 2016. Semen qualities were evaluated on volume $(\mathrm{ml})$, $\mathrm{pH}$, sperm concentration $\left(\times 10^{6} \mathrm{~mL}\right)$, sperm motility (\%), sperm life (\%), sperm primary abnormality (\%) and secondary abnormality (\%) followed with group comparison using t-test. Results shows that bulls at 4 and 7 years old have semen qualities at volume $4.55 \pm 0.91 \mathrm{ml}$ and $5.18 \pm 1.58 \mathrm{ml}, \mathrm{pH} 6.51 \pm 0.06$ and $6.52 \pm 0.01$, sperm concentration $962.30 \pm 390.50 \times 10^{6} / \mathrm{ml}$ and $1079 \pm 90.56 \times 10^{6} / \mathrm{ml}$, sperm motility $68.00 \pm 3.11 \%$ and $66.04 \pm 6.30 \%$, sperm life $71.88 \pm 2.58 \%$ and $72.02 \pm 1.35 \%$, sperm primary abnormality $1.05 \pm 0.20 \%$ and $0.93 \pm 0.14 \%$ and sperm secondary abnormality $3.54 \pm 0.48 \%$ and $4.24 \pm 0.31 \%$ respectively. In this study, bulls age was significantly affected to volume and sperm secondary abnormality $(P<0.05)$ parameters. It is concluded that Bali cattle at 7 years old produce more semen volume and more number of sperm with secondary abnormality compared with bulls at 4 years old.
\end{abstract}

Keywords: Bali cattle, age effect, fresh semen quality

\section{Pendahuluan}

Sapi Bali merupakan sapi lokal Indonesia dengan keunggulan cocok pada lingkungan tropis sehingga dapat berkembang biak dengan baik dan mempunyai kualitas karkas yang tinggi (Prastowo, Widi, \& Widyas, 2017). Upaya yang dilakukan untuk menunjang keunggulan sapi Bali tersebut adalah dengan meningkatkan kualitas genetik pada aspek produktivitas (Widyas, Nugroho, \& Prastowo, 2017), salah satunya adalah menggunakan teknologi reproduksi untuk penyebaran genetik dari pejantan yang terseleksi (Ax et al., 2016). Salah satu teknologi reproduksi yang telah 
berhasil dan banyak digunakan untuk penyebaran genetik pejantan adalah Inseminasi Buatan (IB). Inseminasi Buatan merupakan teknologi reproduksi yang meliputi koleksi atau penampungan semen, proses dan pengolahan semen dan menempatkannya pada organ reproduksi betina (Toelihere, 1993a). Dijelaskan lebih lanjut bahwa, tingkat keberhasilan IB sangat dipengaruhi oleh empat faktor yang saling berhubungan yaitu kualitas semen, pemilihan sapi betina akseptor, akurasi deteksi birahi dan keterampilan inseminator (Susilawati, 2013).

Umur merupakan salah satu faktor yang memengaruhi produksi dan kualitas semen yang dihasilkan seekor pejantan (Bhakat et al., 2011). Seiring dengan bertambahnya umur, pejantan akan menghasilkan semen dengan volume yang cenderung meningkat (Dewi, Ondho, \& Kurnianto, 2012; Wahyuningsih, Saleh, \& Sugiyatno, 2013), motilitas menurun dan meningkatnya jumlah spermatozoa yang abnormal (Brito et al., 2002). Kualitas semen dari seekor pejantan berhubungan erat dengan fertilitas (Mishra, Palai, Sarangi, Prusty, \& Maharana, 2013; Morrell et al., 2017) dan memiliki arti ekonomis yang tinggi pada program produksi ternak (Han \& Peñagaricano, 2016).

Berdasarkan hal tersebut, penelitian ini bertujuan untuk mengetahui pengaruh umur sapi Bali terhadap kualitas semen segar sebagai salah satu cara untuk mengevaluasi tingkat fertilitas pejantan. Selain itu, informasi kualitas semen segar yang diperoleh juga dapat digunakan sebagai dasar untuk menentukan umur atau lama pemeliharaan pejantan sebagai sumber semen.

\section{Materi dan Metode \\ Materi penelitian}

Materi yang digunakan adalah semen segar yang ditampung dari 8 ekor sapi Bali berumur 4 dan 7 tahun (masing-masing 4 ekor) yang dipelihara oleh Balai Besar Inseminasi Buatan (BBIB) Singosari Malang Jawa Timur pada periode September - November 2016. Rata-rata bobot badan sapi Bali pada umur 4 dan 7 tahun adalah $656,75 \pm 32,69 \mathrm{Kg}$ dan $615,5 \pm 72,59 \mathrm{Kg}$ dengan lingkar skrotum $27,5 \pm 1,64 \mathrm{~cm}$ dan $27,93 \pm 0,74 \mathrm{~cm}$. Sapi-sapi tersebut dipelihara dalam kandang individu dengan perawatan rutin kandang dibersihkan, dimandikan dan diberi pakan berupa hijauan, silase dan konsentrat sebanyak dua kali sehari sesuai dengan kebutuhan nutrisi. Suplemen nutrisi dalam bentuk mineral blok dan air minum juga diberikan secara ad libitum.

\section{Metode penelitian Penampungan semen}

Semen ditampung sebanyak dua kali dalam satu minggu menggunakan vagina buatan dan pada setiap penampungan diambil sebanyak satu ejakulasi (ejakulat pertama). Tata cara standar pada pembersihan tempat penampungan, preputium dan membiarkan pejantan melakukan false mounting (3-5 kali) dilakukan pada semua pejantan sebelum ditampung. Tujuan dari perlakuan false mounting adalah untuk memaksimalkan stimulasi sexual sehingga menghasilkan produksi semen yang maksimal (Schenk, 2018).

\section{Evaluasi kualitas semen}

Kualitas semen segar dievaluasi pada parameter volume $(\mathrm{ml}), \mathrm{pH}$, konsentrasi $\left(\times 10^{6} / \mathrm{ml}\right)$, motilitas $(\%), \quad$ persentase spermatozoa hidup (L/D; \%), abnormalitas primer (\%) dan abnormalitas sekunder (\%). Volume diamati langsung pada tabung penampung semen sesaat setelah penampungan dengan satuan mililiter $(\mathrm{ml})$, sementara $\mathrm{pH}$ diamati dengan meneteskan semen pada $\mathrm{pH}$ indikator.

Perhitungan konsentrasi spermatozoa dilakukan dengan cara mencampur sampel semen sebanyak $0,035 \mathrm{ml}$ dengan larutan $\mathrm{NaCl}$ fisiologis $0,9 \%$ sebanyak $3,5 \mathrm{ml}$. Larutan tersebut selanjutnya dihomogenkan selama 5 7 detik, kemudian dipindahkan ke dalam cuvet untuk diukur konsentrasinya menggunakan spektrofotometer. Satuan konsentrasi dalam penelitian ini adalah $10^{6}$ sel spermatozoa per mililiter $\left(\times 10^{6} / \mathrm{ml}\right)$.

Motilitas spermatozoa ditentukan dengan meneteskan sampel semen pada slide glass kemudian ditutup menggunakan cover glass dan selanjutnya diamati menggunakan mikroskop (perbesaran 400x). Motilitas dinilai secara subjektif dengan melihat banyaknya spermatozoa yang bergerak lurus kedepan (progresif). Adapun standar penilaian motilitas berada para kisaran 0 - 100\% (Toelihere, 1993b).

Persentase spermatozoa hidup (Life/Dead rasio; L/D) dilakukan dengan metode 
pewarnaan dan preparat ulas. Sebanyak $2 \mu 1$ sampel semen segar dicampur dengan $10 \mu \mathrm{l}$ eosin-nigrosin kemudian dibuat preparat ulas, dikeringkan dan selanjutnya diamati menggunakan mikroskop (perbesaran 400x). Spermatozoa mati akan menyerap warna merah pada bagian kepala (Hafez \& Hafez, 2000). Jumlah spermatozoa yang diamati minimal sebanyak 200, selanjutnya prosentase spermatozoa hidup dapat dihitung. Preparat ulas yang sama juga digunakan untuk pemeriksaan spermatozoa yang memiliki abnormalitas primer dan sekunder. Abnormalitas primer diamati pada bagian kepala, sedangkan abnormalitas sekunder diamati pada bagian ekor (Shukla, 2011). Jumlah spermatozoa yang diamati minimal sebanyak 200 dan selanjutnya persentase abnormalitas dapat dihitung.

\section{Analisis data}

Data kualitas semen segar antar kelompok umur dibandingkan secara statistik menggunakan $t$-test dengan bantuan aplikasi $\mathrm{R}$ (R Core Team, 2016) pada $\alpha=5 \%$. Perbedaan antar kelompok umur pada masing-masing parameter kualitas semen dikategorikan nyata apabila nilai $\mathrm{P}<0,05$.

\section{Hasil dan Pembahasan \\ Data kualitas semen segar sapi Bali}

Hasil evaluasi kualitas semen segar selama penampungan dari 8 ekor pejantan sapi Bali dapat dilihat pada Tabel 1. Pengamatan kualitas semen secara langsung setelah penampungan diperoleh volume dan $\mathrm{pH}$ berkisar dari 0,40-4,83 $\mathrm{ml}$ dan 6,20-6,51. Beberapa penelitian sebelumnya melaporkan bahwa volume dan $\mathrm{pH}$ semen segar sapi Bali adalah 3,07-3,18 $\mathrm{ml}$ dan 7 (Haryani, Latief, Sonjaya, \& Yusuf, 2016), 5,5 $\mathrm{ml}$ dan 6 (Savitri, Suharyati, \& Siswanto, 2014), $5 \mathrm{ml}$ dan 6 (Soi, 2016). Dapat dijelaskan bahwa volume semen dipengaruhi oleh genetik, lingkungan (Mathevon, Buhr, \& Dekkers, 1998) dan juga metode penampungan semen (León, Porras, Galina, \& Navarro-Fierro, 1991). pH merupakan cerminan metabolisme spermatozoa, nilainya dipengaruhi oleh metode koleksi semen (León et al., 1991), selain itu $\mathrm{pH}$ juga berhubungan erat dengan gerak kinetik spermatozoa dan fertilitasnya (Contri et al., 2013).

Perhitungan konsentrasi spermatozoa diperoleh pada kisaran $294-1676,00 \times 10^{6} / \mathrm{ml}$, sedangkan motilitas berkisar pada $35-75 \%$. Konsentrasi spermatozoa dan volume semen menentukan jumlah total spermatozoa yang terkandung dalam setiap ejakulat. Kedua parameter tersebut selanjutnya menjadi dasar perhitungan jumlah bahan pengencer semen yang harus ditambahkan dan pada akhirnya menentukan jumlah dosis semen beku yang dihasilkan (Baracaldo, Barth, \& Bertrand, 2007). Terkhusus pada parameter motilitas, BBIB Singosari mensyaratkan minimal $60 \%$ untuk dapat diproses lebih lanjut menjadi semen beku. Hal demikian menjadi salah satu pertimbangan karena pada proses pembekuan semen, motilitas sperma akan mengalami penurunan kurang lebih $20-30 \%$ pada sapi Bali (Hapsari, Khalifah, Widyas, Pramono, \& Prastowo, 2018). Seperti yang dilaporkan pada penelitian-penelitian sebelumnya, motilitas memiliki korelasi positif terhadap fertilitas pejantan (Januskauskas, Johannisson, \& Rodriguez-Martinez, 2001; Morrell et al., 2017).

Secara umum diperoleh rata-rata persentase L/D spermatozoa sebesar $71,95 \pm 7,90 \%$. Semen segar dapat diproses menjadi semen beku apabila memiliki jumlah spermatozoa hidup minimal 70\% (Shukla, 2011), dengan demikian semen sapi Bali yang ditampung dalam penelitian ini memenuhi persyaratan tersebut dan dapat diolah menjadi semen beku.

Tabel 1. Kualitas semen segar sapi Bali selama penampungan $(n=80$ ejakulat)

\begin{tabular}{lrrr}
\hline \multicolumn{1}{c}{ Parameter } & \multicolumn{1}{c}{ Minimal } & \multicolumn{1}{c}{ Maksimal } & Rata-rata \pm SD \\
\hline Volume $(\mathrm{ml})$ & 0,40 & 8,80 & $4,83 \pm 1,40$ \\
$\mathrm{pH}$ & 6,20 & 6,80 & $6,51 \pm 0,12$ \\
Konsentrasi $\left(\times 10^{6} / \mathrm{ml}\right)$ & 294,00 & 1676,00 & $1020,90 \pm 316,80$ \\
Motilitas $(\%)$ & 35,00 & 75,00 & $67,02 \pm 6,92$ \\
L/D (\%) & 52,00 & 95,00 & $71,95 \pm 7,90$ \\
Abnormalitas Primer (\%) & 0,00 & 2,86 & $0,99 \pm 0,63$ \\
Abnormalitas Sekunder (\%) & 0,85 & 9,49 & $3,89 \pm 1,43$ \\
\hline
\end{tabular}


Persentase spermatozoa yang memiliki abnormalitas primer pada penelitian ini berkisar antara $0-2,86 \%$, sedangkan abnormalitas sekunder adalah 0,85-9,49\%. Hasil ini masih berada pada kisaran yang dapat diterima $(<20 \%)$ sehingga dapat diproses menjadi semen beku (Toelihere, 1993b). Kualitas semen pada volume, $\mathrm{pH}$, konsentrasi, $\mathrm{L} / \mathrm{D}$, motilitas dan abnormalitas pada semen segar dipengaruhi oleh banyak faktor diantaranya kondisi masing-masing individu seperti kualitas organ reproduksi, umur ternak, kondisi manajemen peternakan, jenis pakan yang diberikan dan bangsa sapi yang digunakan (Gordon, 2005). Penjagaan terhadap faktor manajemen pemeliharaan terutama asupan nutrisi menjadi penting dalam menghasilkan semen yang layak untuk diproses menjadi semen beku. Selain itu, manajemen penampungan semen untuk memaksimalkan spermatoza yang dihasilkan dengan meminimalisir kerusakan juga perlu diperhatikan dalam hal ini, terlebih pada pejantan-pejantan yang memiliki kualitas genetik tinggi dan digunakan sebagai sumber semen pada balai inseminasi buatan.

\section{Pengaruh umur pejantan terhadap kualitas semen segar}

Hasil analisis menunjukkan bahwa umur pejantan memberi pengaruh yang signifikan $(\mathrm{P}<0,05)$ terhadap volume semen (Tabel 2). Rata-rata volume semen segar pada kelompok pejantan berumur 7 tahun lebih tinggi dibandingkan dengan umur 4 tahun. Penelitian sebelumnya melaporkan bahwa volume semen yang dihasilkan akan bertambah seiring dengan umur pejantan (Brito et al., 2002). Pertambahan umur berkorelasi positif dengan ukuran testis (Perumal, 2014), terutama pada lingkar skrotum dan kapasitas produksi spermatozoa harian (Pant et al., 2003). Dilaporkan pula pada sapi Bali, volume semen berkorelasi positif dengan lingkar skrotum dan konsentrasi spermatozoa dengan nilai koefisien korelasinya (r) sebesar masingmasing 0,63 dan 0,60 (Saputra, Ihsan, \& Isnaini, 2017). Dalam penelitian ini didapatkan konsentrasi spermatozoa pada kelompok umur 7 tahun lebih tinggi dibandingkan umur 4 tahun, meskipun secara statistik tidak berbeda nyata $(\mathrm{P}>0,05$; Tabel 2). Dijelaskan lebih lanjut bahwa peningkatan umur mengakibatkan pertambahan jumlah tubuli seminiferi testis, sehingga jumlah spermatozoa yang diproduksi juga meningkat. Hal ini terkonfirmasi pada nilai lingkar skrotum sapi Bali yang digunakan dalam penelitian ini yaitu rata-rata ukuran lingkar skrotum sapi Bali yang berumur 7 tahun $(27,93 \pm 0,74 \mathrm{~cm})$ lebih besar dibandingkan umur 4 tahun $(27,5 \pm 1,64$ $\mathrm{cm})$.

Nilai $\mathrm{pH}$ semen antar kelompok umur dalam penelitian ini tidak berbeda nyata $(\mathrm{P}>0,05)$. Rata-rata nilai $\mathrm{pH}$ pada umur 4 dan 7 tahun sebesar $6,51 \pm 0,06$ dan $6,52 \pm 0,01$, nilai tersebut berada pada kisaran normal sesuai dengan standar BBIB Singosari. Penelitian sebelumnya melaporkan bahwa pada sapi Jawa, umur tidak memengaruhi $\mathrm{pH}$ semen (Dewi et al., 2012). pH semen lebih banyak ditentukan oleh kondisi dan komposisi pakan yang memengaruhi sekresi seminal plasma dari kelenjar-kelenjar aksesoris organ reproduksi jantan. Seperti diketahui bahwa seminal plasma terdiri dari karbohidrat dan ion-ion lain yang mendukung kehidupan spermatozoa (Hafez \& Hafez, 2000). pH semen perlu diperhatikan karena dapat digunakan sebagai indikator metabolisme semen, $\mathrm{pH}$ yang tinggi atau rendah dapat mengakibatkan penurunan motilitas spermatozoa yang berakibat pada fertilitasnya (Contri et al., 2013; Zhou et al., 2015). Akibat tidak berbedanya nilai $\mathrm{pH}$ semen antar kelompok umur, maka motilitas spermatozoa yang diperoleh juga tidak berbeda nyata $(P>0,05)$ dalam penelitian ini. Selanjutnya dapat dikatakan bahwa sapi Bali yang berumur 4 dan 7 tahun mensekresikan komponen seminal plasma yang hampir sama dan tidak mengakibatkan perbedaan metabolisme semen yang memegaruhi motilitas spermatozoa.

Persentase L/D spermatozoa pada sapi Bali kelompok umur 4 dan 7 tahun tidak berbeda nyata $(\mathrm{P}>0,05)$. Hal yang sama juga diperoleh pada nilai abnormalitas primer antar kelompok umur tidak berbeda, akan tetapi pada abnormalitas sekunder berbeda nyata $(\mathrm{P}<0,05)$. Penelitian sebelumnya melaporkan bahwa L/D tidak dipengaruhi oleh umur pejantan (Melita, Adam, \& Mulyadi, 2014; Ramsiyati, Sriyana, \& Sudarmadi, 2004), diperkirakan L/D lebih banyak dipengaruhi oleh faktor penanganan semen pasca penampungan. 
Tabel 2. Hasil pemeriksaan kualitas semen segar sapi Bali pada kelompok umur yang berbeda.

\begin{tabular}{lcrrrr} 
Parameter & $\begin{array}{c}\text { Umur } \\
\text { (tahun) }\end{array}$ & Minimal & Maksimal & Rata-rata \pm SD & Nilai P \\
\hline Volume (ml) & 4 & 2,80 & 7,20 & $4,48 \pm 0,91$ & 0,03 \\
& 7 & 2,80 & 8,80 & $5,18 \pm 1,58$ & \\
pH & 4 & 6,40 & 6,80 & $6,51 \pm 0,06$ & 0,92 \\
& 7 & 6,20 & 6,80 & $6,52 \pm 0,01$ & \\
Konsentrasi & 4 & 394,00 & 1676 & $962,27 \pm 390,50$ & 0,08 \\
$\left(\times 10^{6} / \mathrm{ml}\right)$ & 7 & 647,00 & 1452 & $1079,45 \pm 90,56$ & \\
Motilitas (\%) & 4 & 35,00 & 75,00 & $68,00 \pm 3,11$ & 0,20 \\
& 7 & 40,00 & 75,00 & $66,04 \pm 6,30$ & \\
L/D (\%) & 4 & 54,00 & 95,00 & $71,87 \pm 2,58$ & 0,93 \\
& 7 & 52,00 & 92,00 & $72,02 \pm 1,35$ & \\
Abnormalitas primer & 4 & 0,00 & 2,86 & $1,05 \pm 0,20$ & 0,39 \\
$(\%)$ & 7 & 0,00 & 2,19 & $0,93 \pm 0,14$ & \\
Abnormalitas sekunder & 4 & 0,85 & 6,85 & $3,54 \pm 0,48$ & 0,02 \\
$(\%)$ & 7 & 1,45 & 9,49 & $4,24 \pm 0,31$ & \\
\hline
\end{tabular}

$\mathrm{P}<0,05$ : berbeda nyata

Hal demikian didukung oleh hasil perhitungan abnormalitas sekunder yang berbeda nyata $(\mathrm{P}<0,05)$. Berdasarkan penyebabnya, abnormalitas primer merupakan kelainan pada kepala spermatozoa yang terjadi ketika masih berada di dalam tubuli seminiferi sementara abnormalitas sekunder ditandai dengan kelainan pada ekor spermatozoa yang terjadi setelah proses spermatogenesis hingga ejakulasi dan saat proses penanganan (Hafez \& Hafez, 2000). Ditambahkan bahwa abnormalitas primer ditandai dengan adanya kelainan pada ekor seperti ekor melengkung, melingkar dan patah (Susilawati, 2013). Perbedaan nilai abnormalitas sekunder tersebut dimungkinkan karena perbedaan penanganan pasca penampungan sebelum masuk tahap evaluasi kualitas semen, akan tetapi hal ini perlu dievaluasi dan dibuktikan lebih lanjut. Nilai abnormalitas primer maupun sekunder pada kedua kelompok umur pada penelitian ini diperoleh $<20 \%$ sehingga masih layak diproses lebih lanjut menjadi semen beku (Toelihere, 1993b).

\section{Kesimpulan}

Umur pejantan sapi Bali pada penelitian ini memengaruhi kualitas semen pada parameter volume dan abnormalitas sekunder. Kelompok pejantan dengan umur 7 tahun menghasilkan volume semen dan abnormalitas sekunder lebih tinggi dibandingkan umur 4 tahun. Selanjutnya, umur tidak berpengaruh pada $\mathrm{pH}$, konsentrasi, motilitas, L/D dan abnormalitas primer.

\section{Ucapan terimakasih}

Penelitian ini merupakan bagian dari penelitian Hibah Manajemen Riset Group (MRG) Reproduksi, Pemuliaan dan Biostatistika Ternak dengan judul "Pengaruh Musim pada Karakteristik Ejakulat dan Ketahanan Pasca Pembekuan Semen Sapi Bali" yang dibiayai dana PNBP Universitas Sebelas Maret, tahun anggaran 2017.

\section{Daftar Pustaka}

Ax, R. L., Dally, M. R., Didion, B. A., Lenz, R. W., Love, C. C., Varner, D. D., ... Bellin, M. E. (2016). Artificial Insemination. In Reproduction in Farm Animals (pp. 376-389). http://doi.org/10.1002/9781119265306.c h26

Baracaldo, M. I., Barth, A. D., \& Bertrand, W. (2007). International Veterinary Information Service, Ithaca NY (www.ivis.org), Last updated: 30-Jan. IVIS Reviews in Veterinary Medicine IVIS Ed, 1-11. Retrieved from www.ivis.org

Bhakat, M., Mohanty, T. K., Raina, V. S., Gupta, A. K., Khan, H. M., Mahapatra, R. K., \& Sarkar, M. (2011). Effect of age and season on semen quality parameters 
in Sahiwal bulls. Tropical Animal Health and Production, 43(6), 1161-1168. http://doi.org/10.1007/s11250-011-98171

Brito, L. F. C., Silva, A. E. D. F., Rodrigues, L. H., Vieira, F. V, Deragon, L. A. G., \& Kastelic, J. P. (2002). Effects of environmental factors, age and genotype on sperm production and semen quality in Bos indicus and Bos taurus AI bulls in Brazil. Animal Reproduction Science, 70(3-4), 181-90. Retrieved from http://www.ncbi.nlm.nih.gov/pubmed/11 943488

Contri, A., Gloria, A., Robbe, D., Valorz, C., Wegher, L., \& Carluccio, A. (2013). Kinematic study on the effect of $\mathrm{pH}$ on bull sperm function. Animal Reproduction Science, 136(4), 252-259. http://doi.org/10.1016/j.anireprosci.2012. 11.008

Dewi, A. S., Ondho, Y. S., \& Kurnianto, E. (2012). Kualitas semen berdasarkan umur pada sapi jantan jawa. Animal Agriculture Journal, 1(2), 126-133.

Gordon, I. (2005). Reproductive Technologies in Farm Animals. CABI Publishing.

Hafez, E., \& Hafez, B. (2000). Reproductin in farm animals (7th ed.). Mayland: Lippincott Williams \& Wilkins.

Han, Y., \& Peñagaricano, F. (2016). Unravelling the genomic architecture of bull fertility in Holstein cattle. $B M C$ Genetics, 17(1), 1-11. http://doi.org/10.1186/s12863-016-04546

Hapsari, R. D., Khalifah, Y., Widyas, N., Pramono, A., \& Prastowo, S. (2018). Age effect on post freezing sperm viability of Bali cattle (Bos javanicus). IOP Conference Series: Earth and Environmental Science, 142(1), 012007. http://doi.org/10.1088/17551315/142/1/012007

Haryani, R., Latief, A., Sonjaya, H., \& Yusuf, M. (2016). Characteristic of Bali Bulls Sperms Assessed Using Computerized Assisted Semen Analysis ( CASA ). International Journal of Sciences: Basic and Applied Research, 4531, 161-168.

Januskauskas, A., Johannisson, A., \& Rodriguez-Martinez, H. (2001). Assessment of sperm quality through fluorometry and sperm chromatin structure assay in relation to field fertility of frozen-thawed semen from Swedish AI bulls. Theriogenology, 55(4), 947961. http://doi.org/10.1016/S0093691X(01)00456-3

León, H., Porras, A. A., Galina, C. S., \& Navarro-Fierro, R. (1991). Effect of the collection method on semen characteristics of Zebu and European type cattle in the tropics. Theriogenology, 36(3), 349-355. http://doi.org/10.1016/0093691X(91)90463-N

Mathevon, M., Buhr, M. M., \& Dekkers, J. C. (1998). Environmental, management, and genetic factors affecting semen production in Holstein bulls. Journal of Dairy Science, 81(12), 3321-3330. http://doi.org/10.3168/jds.S00220302(98)75898-9

Melita, D., Adam, \& Mulyadi, D. (2014). Pengaruh umur pejantan dan frekuensi ejakulasi terhadap kualitas spermatozoa sapi aceh. Jurnal Medika Veterinaria, 8, 15-19.

Mishra, C., Palai, T. K., Sarangi, L. N., Prusty, B. R., \& Maharana, B. R. (2013). Candidate gene markers for sperm quality and fertility in bulls. Veterinary World, 6, 905-910. http://doi.org/10.14202/vetworld.2013.90 5-910

Morrell, J. M., Nongbua, T., Valeanu, S., Lima Verde, I., Lundstedt-Enkel, K., Edman, A., \& Johannisson, A. (2017). Sperm quality variables as indicators of bull fertility may be breed dependent. Animal Reproduction Science, 185, 42-52. http://doi.org/10.1016/j.anireprosci.2017. 08.001

Pant, H. C., Sharma, R. K., Patel, S. H., Shukla, H. R., Mittal, A. K., Kasiraj, R., ... Prabhakar, J. H. (2003). Testicular development and its relationship to semen production in Murrah buffalo bulls. Theriogenology, 60(1), 27-34. http://doi.org/10.1016/S0093691X(02)01037-3

Perumal, P. (2014). Scrotal Circumference and Its Relationship with Testicular Growth, Age, and Body Weight in Tho Tho (Bos indicus ) Bulls. International Scholarly Research Notices, 2014, 1-6. http://doi.org/10.1155/2014/249537 
Prastowo, S., Widi, T., \& Widyas, N. (2017). Preliminary analysis on hybrid vigor in Indonesian indigenous and crossbred cattle population using data from published studies. IOP Conference Series: Materials Science and Engineering, 193(1), 012028. http://doi.org/10.1088/1757$899 X / 193 / 1 / 012028$

R Core Team. (2016). R: A language and environment for statistical computing. Vienna, Austria: $\mathrm{R}$ Foundation for Statistical Computing. http://doi.org/10.1007/978-3-540-746867

Ramsiyati, D. T., Sriyana, \& Sudarmadi, B. (2004). Evaluasi kualitas semen sapi potong pada berbagai umur di peternakan rakyat. Prosiding Temu Teknis Nasional Tenaga Fungsional Pertanian, 82-87.

Saputra, D., Ihsan, M., \& Isnaini, N. (2017). Korelasi Antara Lingkar Skrotum Dengan Volume Semen, Konsentrasi Dan Motilitas Spermatozoa Pejantan Sapi Bali. TERNAK TROPIKA Journal of Tropical Animal Production, 10(2), 5968.

http://doi.org/10.21776/ub.jtapro.2017.01 8.02 .9

Savitri, F. K., Suharyati, S., \& Siswanto. (2014). Kualitas semen beku sapi Bali dengan penambahan berbagai dosis vitamin $\mathrm{C}$ pada bahan pengencer skim kuning telur. Jurnal Ilmiah Peternakan Terpadu. Jurnal Ilmiah Terpadu Peternakan, 2(3), 30-36.

Schenk, J. L. (2018). Review: Principles of maximizing bull semen production at genetic centers. Animal, pp. 1-6.
http://doi.org/10.1017/S17517311180004 72

Shukla, M. K. (2011). Applied Veterinary Andrology and Frozen Semen Technology. New Delhi, India: New India Publising Agency.

Soi, M. N. J. (2016). Uji Viabilitas Spermatozoa Sapi Bali Jantan dengan Menggunakan Larutan Natrium Clorida ( $\mathrm{NaCl}$ ) yang Berbeda Level. Journal of Animal Science (JAS), 1(2502), 28-29.

Susilawati, T. (2013). pedoman inseminasi buatan pada ternak. Malang: Universitas Brawijaya Press.

Toelihere, M. R. (1993a). Fisiologi Reproduksi pada Ternak. Bandung: Angkasa.

Toelihere, M. R. (1993b). Inseminasi Buatan pada Ternak. Bandung: Angkasa.

Wahyuningsih, A., Saleh, D. M., \& Sugiyatno. (2013). Pengaruh umur pejantan dan frekuensi penampungan terhadap volume dan motilitas semen segar sapi simmental di balai inseminasi buatan lembang. Jurnal Ilmiah Peternakan, 1(3), 947953.

Widyas, N., Nugroho, T., \& Prastowo, S. (2017). Rooms for genetic improvement in Indonesian Bali cattle population. IOP Conference Series: Materials Science and Engineering, 193(1), 012037. http://doi.org/10.1088/1757899X/193/1/012037

Zhou, J., Chen, L., Li, J., Li, H., Hong, Z., Xie, M., ... Drevet, J. R. (2015). The semen $\mathrm{pH}$ affects sperm motility and capacitation. PLOS ONE, 10(7), 1-15. http://doi.org/10.1371/journal.pone.0132 974 